Pulsed neutron gamma-ray logging in archaeological site survey

This content has been downloaded from IOPscience. Please scroll down to see the full text. 2013 Meas. Sci. Technol. 24125903

(http://iopscience.iop.org/0957-0233/24/12/125903)

View the table of contents for this issue, or go to the journal homepage for more

Download details:

IP Address: 150.146.205.185

This content was downloaded on 19/11/2013 at 11:03

Please note that terms and conditions apply. 


\title{
Pulsed neutron gamma-ray logging in archaeological site survey
}

\author{
A Miceli ${ }^{1}$, G Festa $^{2}$, G Gorini $^{2}$, R Senesi $^{1,3}$ and C Andreani $^{1}$ \\ ${ }^{1}$ University of Rome Tor Vergata, Physics Department and NAST Centre, via della Ricerca Scientifica 1, \\ I-00133 Rome, Italy \\ ${ }^{2}$ University of Milan Bicocca, Physics Department, Piazza della Scienza 3, Milan I-20126, Italy \\ ${ }^{3}$ CNR-IPCF, viale Ferdinando Stagno d'Alcontres n. 37, Messina I-98158, Italy \\ E-mail: alice.miceli@uniroma2.it
}

Received 19 September 2013

Published 19 November 2013

Online at stacks.iop.org/MST/24/125903

\begin{abstract}
An archaeological survey method based on neutron gamma-ray logging is described. The method relies on the measurement of capture gamma radiation induced by neutron irradiation from a pulsed generator. This technique provides elemental information on the irradiated zone by spectroscopic analysis of the gamma-ray data. This approach has been studied with Geant 4 Monte Carlo simulations. In particular, irradiation volume for a deuterium-deuterium and deuterium-tritium (D-T) neutron generator and sampling volume for the D-T source were estimated. In addition, a neutron log response, which illustrates the capability of the neutron tool to localize artifacts lying beneath the surface, is shown.
\end{abstract}

Keywords: Monte Carlo simulation, neutron gamma logging, archaeology, site survey

(Some figures may appear in colour only in the online journal)

\section{Introduction}

Site survey is of paramount importance in archaeology [1]. Archaeological survey consists in the localization and study of an archaeological site before the starting of the actual excavation. It is commonly divided into aerial, surface and subsurface surveys. Aerial surveys are used to locate sites within large areas. Surface surveys are employed to study surface features. Subsurface surveys are used to locate features and artifacts lying beneath the surface. Neutron gamma logging, a nuclear technique, has the potential to be used as a subsurface testing method. Neutron gamma logging is element-selective and can penetrate several tens of centimeters in soil. Its most common application is in the oil and gas industries [2,3]. The technique consists in the neutron irradiation of a zone of interest and consequent measurement of gamma radiation emitted due to inelastic neutron scattering, capture and radioactive decay. Capture gamma-rays yield information on the elemental composition of the irradiated volume and may be used to pinpoint extraneous material. Previous publications by this group [4, 5] have shown promising results on the application of neutron logging to site survey. This paper will focus on the evaluation of the irradiation volume for a deuterium-tritium (D-T) and a deuterium-deuterium (D-D) neutron generator and on the sampling volume for the D-T generator. In addition, a simulated neutron log response is shown to illustrate the ability of the system to localize a buried sample. These studies have been carried out with Geant4 [6, 7] based Monte Carlo simulations.

\section{Materials and methods}

\subsection{Neutron logging system}

A neutron gamma logging system consists of a pulsed highenergy neutron generator and a gamma-ray detector. During a measurement, the source and detector are lowered into an existing borehole or are mounted behind the drilling head for taking measurements while the borehole is being drilled. The signal is transmitted to the data acquisition system at the surface through a signal cable. Figure 1 depicts a logging system lowered in a borehole. Typical borehole diameters are $12-40 \mathrm{~cm}$. Fast neutrons emitted by the neutron generator are scattered by nuclei in the soil and the borehole surrounding the source. Gamma-rays are emitted in inelastic scattering. 


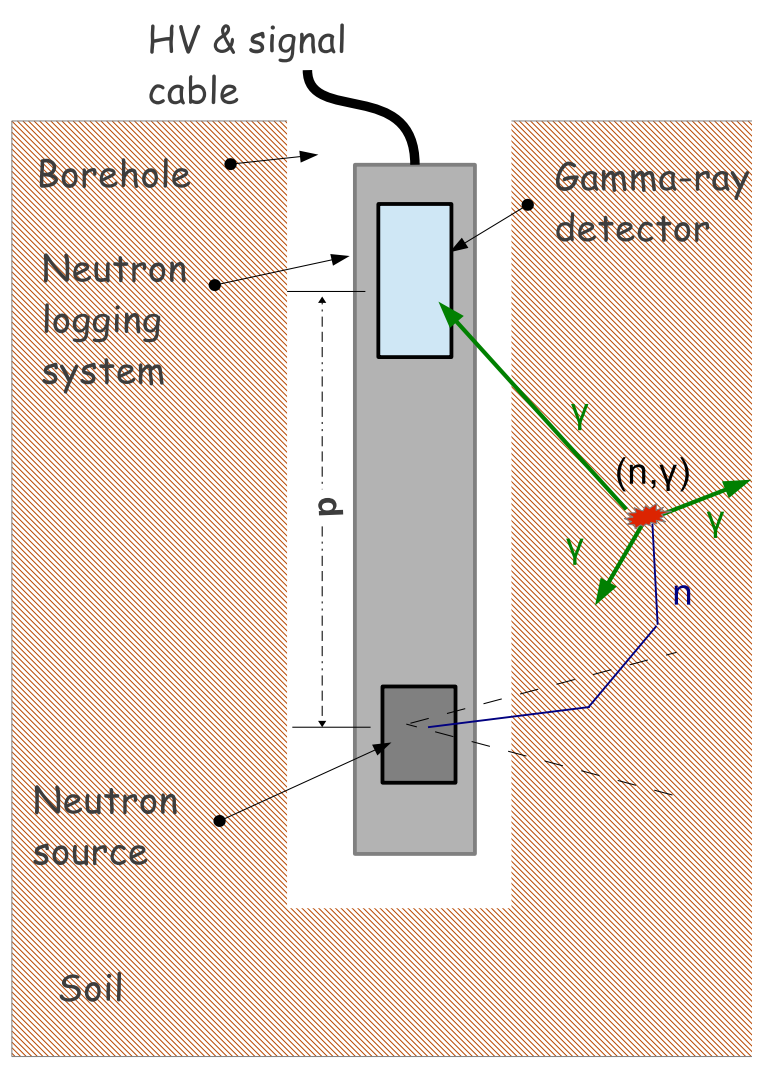

Figure 1. Logging system. The neutron source, gamma-ray detector, logging system casing and HV and signal cable are depicted inside a borehole. A capture event resulting in the detection of a gamma-ray is illustrated.

Following the fast neutron phase, the neutrons are rapidly slowed down by elastic collisions with nuclei. Neutrons continue to slow down till their mean kinetic energies are equal to the vibration energies of the atoms in thermal equilibrium. A cloud of thermal neutrons forms around the source. Collisions between the nuclei and neutrons continue and there is a spreading of the cloud outwards into the soil. During this diffusion phase, occasionally a nucleus will absorb a neutron, resulting in the formation of a compound nucleus [8]. The decay of the compound nucleus takes place in $10^{-16} \mathrm{~s}$. The nucleus reaches its ground state by emitting 2-4 gamma-rays in a cascade (prompt gamma-rays) in $10^{-9}-10^{-12} \mathrm{~s}$ [9]. If the ground state of the daughter nucleus is not stable, radioactive decay will occur. The daughter nucleus mainly decays by the emission of beta particles and gamma-rays [10]. The gamma radiation emitted during inelastic scattering, capture and radioactive decay is measured by the gamma-ray detector. D-T generators are commonly employed as neutron sources. D-T generators emit neutrons of $14 \mathrm{MeV}$ with typical neutron yields of $10^{8}-10^{9} \mathrm{n} \mathrm{s}^{-1}$ and frequency up to $20 \mathrm{~Hz}$. Scintillation crystals, mainly sodium-iodide crystals, are the most widely used detectors for nuclear logging [11].

\subsection{Simulation model}

We simulated a conventional neutron gamma logging system inside a borehole. The system consists of a $14 \mathrm{MeV}$ point source and a gamma-ray detector. The source emits fast

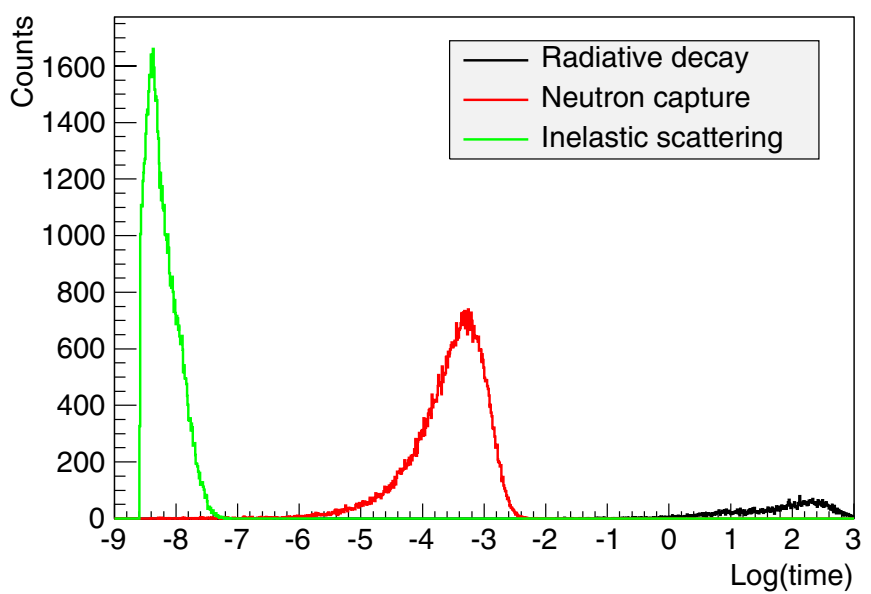

Figure 2. Simulated time distribution on a log scale (base 10) of gamma rays produced by inelastic scattering, neutron capture and delayed activation [5].

neutrons into the borehole and surrounding soil in a $10^{\circ}$ cone along the $z$ axis. The borehole had a diameter of $11 \mathrm{~cm}$. The soil chemical composition was taken from Hoover et al [12]. The detector was located $20 \mathrm{~cm}$ above the source. The detector size was $6.4 \mathrm{~cm}$ in diameter and $9 \mathrm{~cm}$ in length. Neutrons interact in the surrounding material via inelastic and elastic scattering and, once thermalized, undergo radiative thermal neutron capture. Neutron inelastic/elastic scattering and capture were modeled with the Geant 4 High Precision Neutron Model. Neutron capture gamma-rays were modeled by randomly sampling gamma-ray energies from the Evaluated Nuclear Structure Data File. Their direction was randomly distributed. Gamma-rays were tracked using the Geant4 Livermore model. Radioactive nuclei formed by neutron irradiation were modeled with the Geant 4 radioactive process. To study the feasibility of the technique aside from detector effects, we simulated an ideal gamma-ray detector with unit efficiency.

\subsection{Event selection}

Measured gamma-ray spectra contain a large number of peaks generated by neutron capture, scattering and radioactive decay. This results in peaks overlapping and misidentification [13]. To lessen these issues we exploited the pulsed nature of the neutron source [4, 5, 13]. Figure 2 shows the time distribution on a log scale (base 10) of gamma-rays produced by inelastic scattering, neutron capture and radioactive decay. The processes are well separated in time. By selecting the events in the time window $\left[10^{-6}, 10^{-2}\right] \mathrm{s}$ we can select neutron capture gamma-rays [5]. Capture gamma-rays have energy characteristics of the target nucleus and provide information on the isotopic composition of the irradiated material. The intensity of a gamma-ray peak depends on the abundance of that element, thermal neutron capture cross section, sourcedetector configuration and gamma-ray penetration in soil. In order to have information from a larger volume under investigation, we selected only deeply penetrating high-energy gamma rays $(>6.5 \mathrm{MeV})$. 

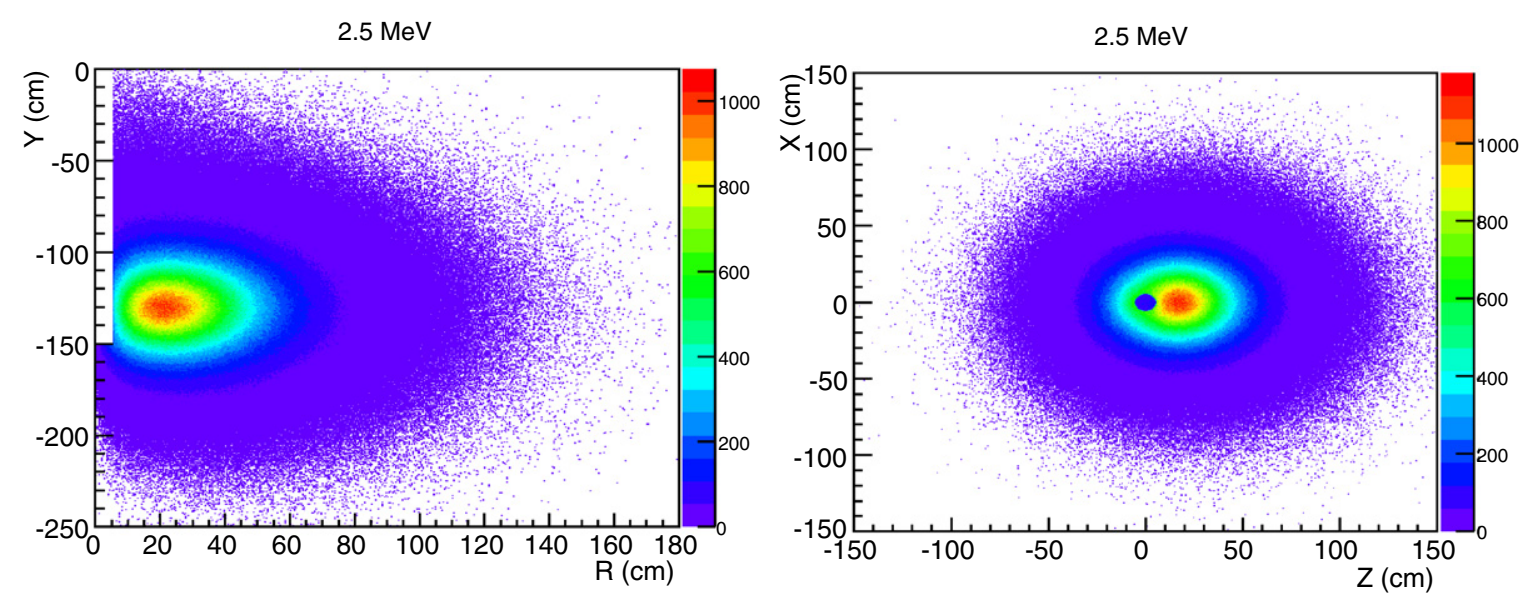

$14 \mathrm{MeV}$

$14 \mathrm{MeV}$
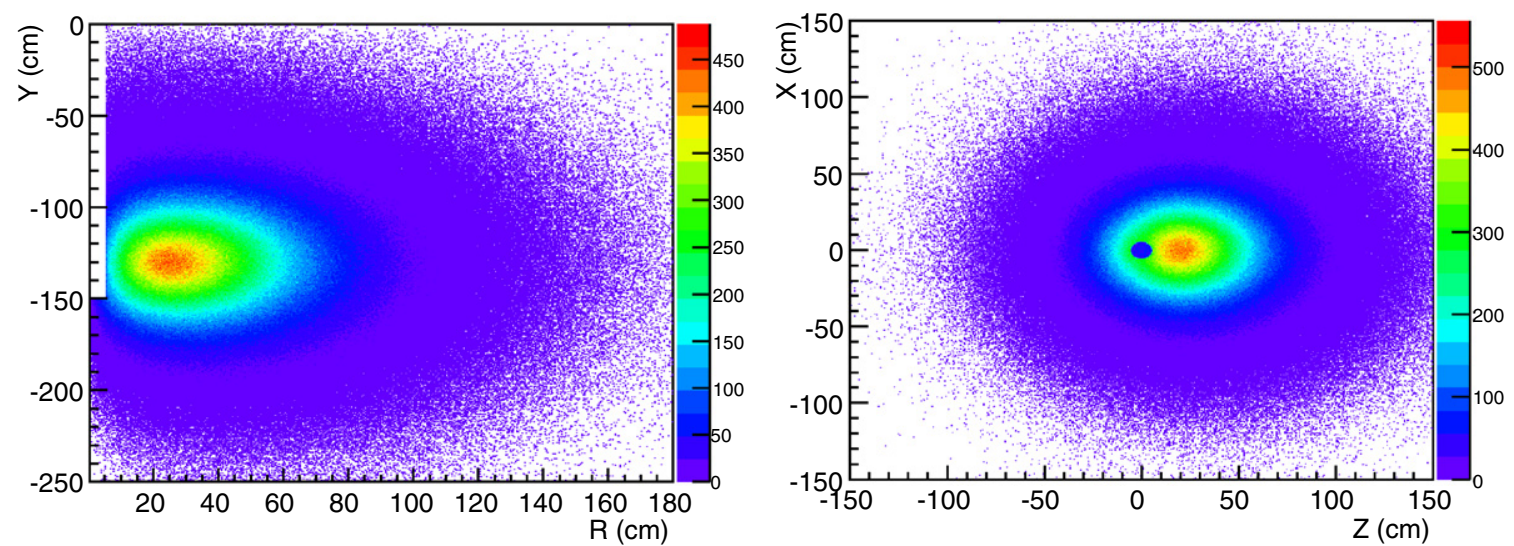

Figure 3. Simulated spatial distribution of neutron capture events for a D-D (top) and a D-T (bottom) neutron generator in a typical soil composition. The borehole depth was $1.5 \mathrm{~m}$.

Table 1. Gamma-ray energies from neutron capture in soil in the energy range 6.5-8 MeV. Numbers in bold are the energies of the strongest peaks.

\begin{tabular}{lcl}
\hline Element & Percentage in soil & Peaks $(\mathrm{MeV})$ \\
\hline $\mathrm{H}$ & 2.1 & - \\
$\mathrm{C}$ & 1.6 & - \\
$\mathrm{O}$ & 57.7 & - \\
$\mathrm{Al}$ & 5.0 & $6.620,6.711,7.693, \mathbf{7 . 7 2 4}$ \\
$\mathrm{Si}$ & 27.1 & 7.199 \\
$\mathrm{~K}$ & 1.3 & $6.999, \mathbf{7 . 7 6 9}$ \\
$\mathrm{Ca}$ & 4.1 & 7.339 \\
$\mathrm{Fe}$ & 1.1 & $7.279, \mathbf{7 . 6 3 1}, 7.646$ \\
\hline
\end{tabular}

\subsection{Neutron log response}

A neutron $\log$ is the record of a quantity of interest, i.e. density or hydrogen content, as a function of the borehole depth. In archaeological site survey applications, the main objective of the technique is locating artifacts lying beneath the surface. To this aim, we simulated the gamma-ray spectra at different depths and searched for peaks corresponding to chemical elements extraneous to the soil. A list of major gamma-rays produced by soil is shown in table 1 . The peak selection algorithm loops through the gamma ray spectrum and stores peaks with intensities $>0.5 \%$ of the strongest peak. The selected peaks are run through a matching algorithm, which compares the peak energy with the Molnar database [9] and, when a match is found, assigns a chemical element to the peak. The capability of the neutron tool to localize artifacts lying beneath the surface was tested by simulating a $\mathrm{Cu}$ cylinder, representing a hypothetical buried artifact, $9 \mathrm{~cm}$ from the center of the borehole, $110 \mathrm{~cm}$ from the surface. The neutron $\log$ response reported here is the number of counts under the strongest copper peak (energy $=7.916 \mathrm{MeV}$ ) as a function of depth.

\section{Results}

\subsection{Irradiation volume}

The volume irradiated by the neutron source depends on the source energy and the soil composition. We simulated a D-T and a D-D neutron source to show the different extent of the thermal neutron cloud in a typical soil composition with two different initial neutron energies. D-D generators emit neutrons of $2.5 \mathrm{MeV}$ and are less common in the well logging industry due to the lower emission rate. Figure 3 shows the simulated spatial distribution for the D-T and the D-D generators. Ten million fast neutrons were emitted forward along the $z$ axis in a $10^{\circ}$ cone. As expected, the density of neutron capture events decreases with the distance from the source. The extent of the thermal neutron cloud is $150 \mathrm{~cm}(120 \mathrm{~cm})$ in the direction of 

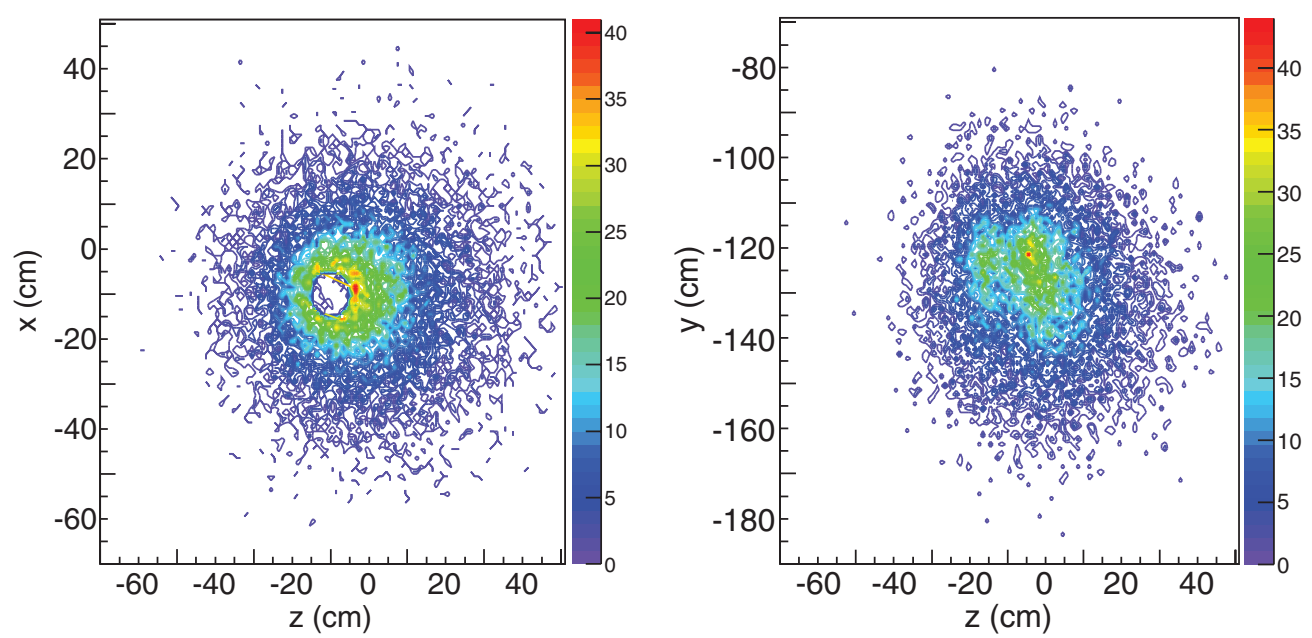

Figure 4. Origin of neutron capture gamma-rays measured by the logging tool. The source energy was $14 \mathrm{MeV}$ and the source-detector spacing was $20 \mathrm{~cm}$. Left: distribution in the $x z$ plane. Right: distribution in the $y z$ plane.
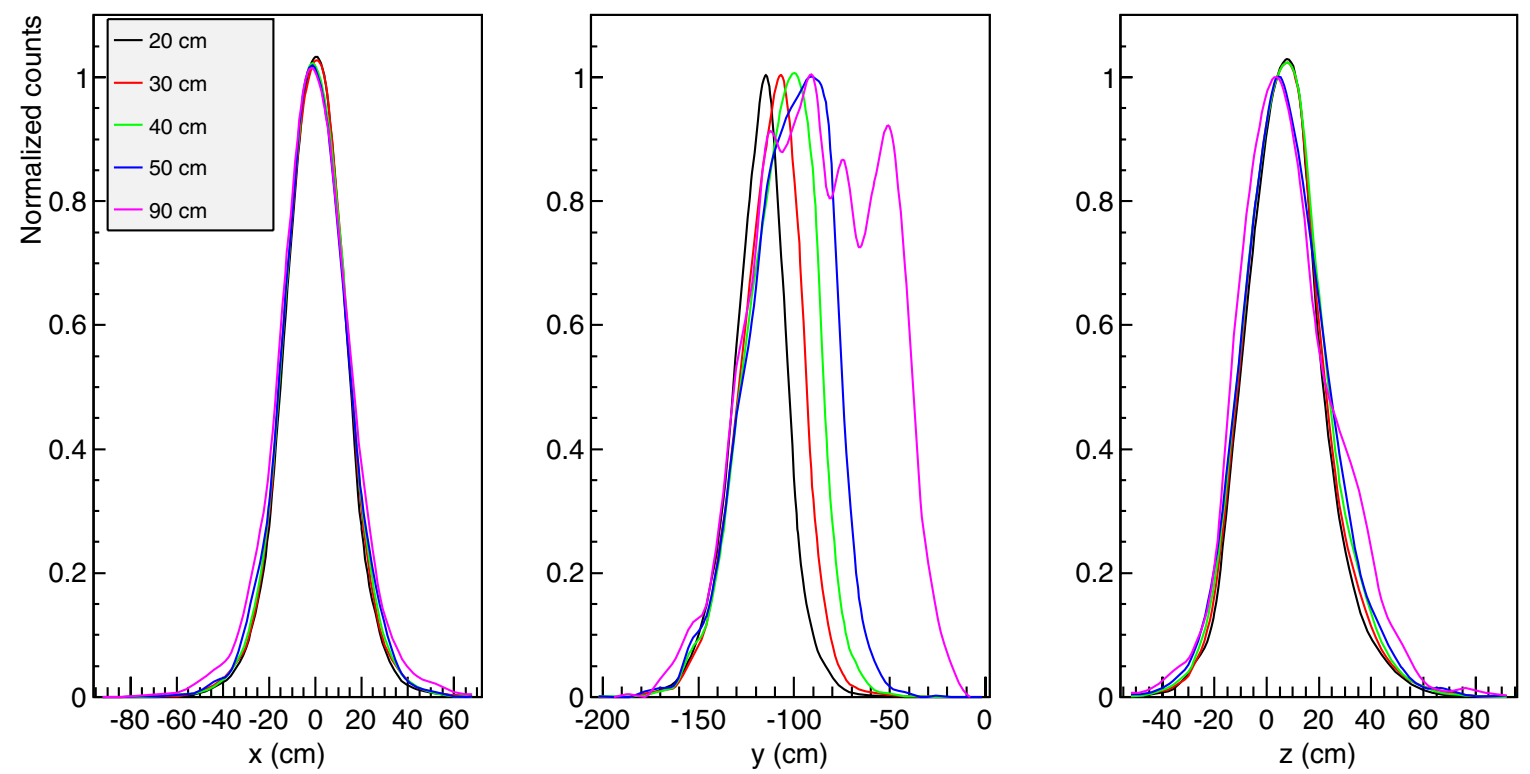

Figure 5. Normalized spatial distribution of neutron capture events which result in detected gamma-rays for the $14 \mathrm{MeV}$ source for 20,30 , 40, 50 and $90 \mathrm{~cm}$ source-detector spacing. Left: spatial distribution along the $x$ axis. Center: spatial distribution along the $y$ axis. Right: spatial distribution along the $z$ axis.

the emission of the neutrons, $100 \mathrm{~cm}(80 \mathrm{~cm})$ in the opposite direction and $110 \mathrm{~cm}(80 \mathrm{~cm})$ along the $x$ and $y$ axes for the D-T (D-D) neutron source.

\subsection{Sampling volume}

The sampling volume of a neutron logging tool is the volume from which a measurable signal can be extracted. Sampling volume depends on the volume irradiated by the source, penetration of gamma-rays in soil and source-detector configuration. In order to estimate the sampling volume, we selected the neutron source with the larger irradiation volume, the D-T neutron source, and simulated five different sourcedetector spacings: 20,30, 40, 50 and $90 \mathrm{~cm}$. Coordinates of neutron capture events resulting in gamma-ray detection were stored. Figure 4 shows the 2D spatial distribution of neutron capture events corresponding to detected gamma-rays for a
$20 \mathrm{~cm}$ source-detector spacing. The gamma radiation detected originates from material within $400 \mathrm{~mm}$ of the borehole wall.

Figure 5 displays the spatial distribution of capture events which result in gamma radiation detection for 20 , $30,40,50$ and $90 \mathrm{~cm}$ source-detector spacing. The values were normalized for the number of events. As expected, the maximum signal is halfway between the source and the detector, hence the measuring point of the logging system will be halfway between the source and the detector. Figure 6 shows the sampling volume and the integrated counts as a function of source-detector spacing. Increasing the source-detector spacing decreases the counts on the gamma-ray detector, whereas it increases the sampling volume. Source-detector spacing should be carefully chosen in order to select the best tradeoff between the count rate and sampling volume for a specific application. Five million histories were simulated for 


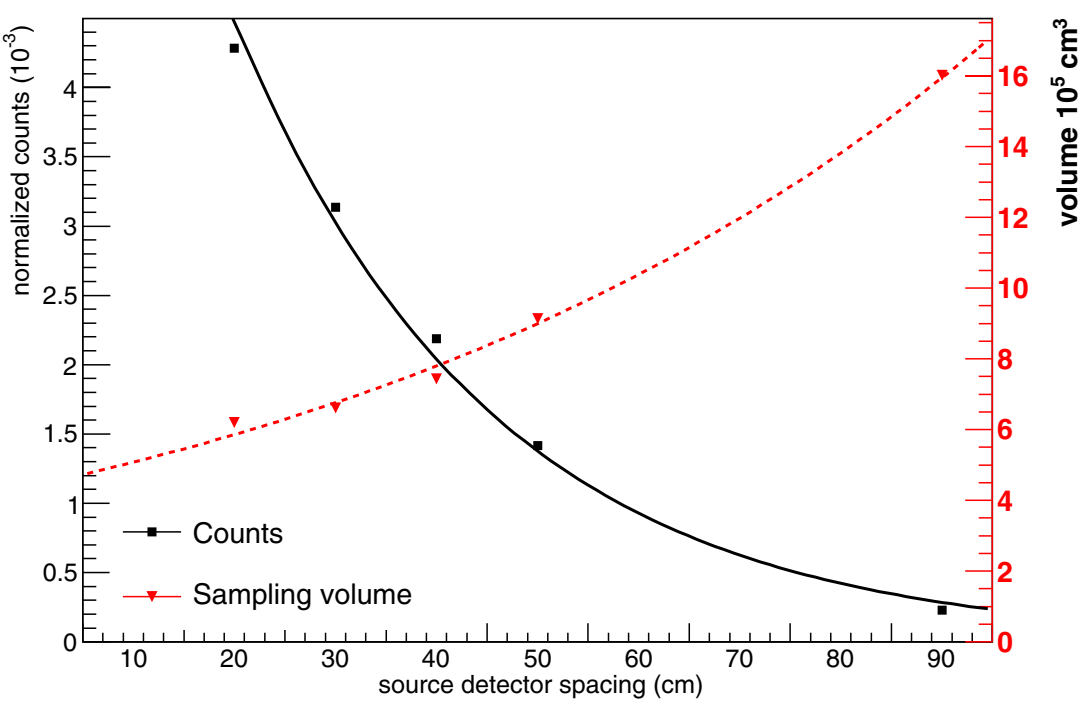

Figure 6. Sampling volume and integrated counts as a function of source-detector spacing for the $14 \mathrm{MeV}$ neutron source.
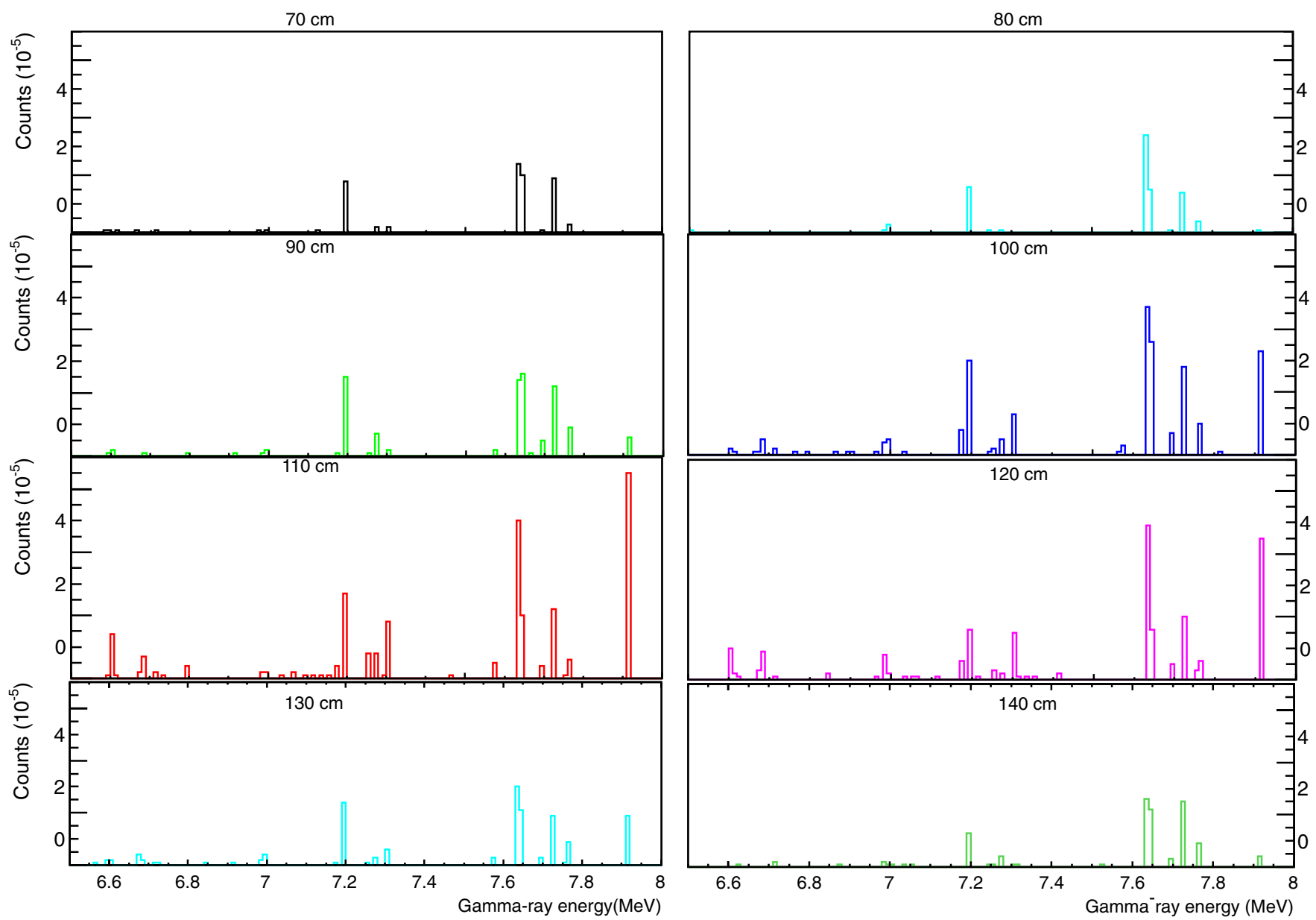

Figure 7. Gamma-ray spectra measured at several depths. A Cu sample is placed at a depth of $110 \mathrm{~cm}$.

the spacings from 20 to $50 \mathrm{~cm}$. Ten million histories were simulated for the $90 \mathrm{~cm}$ spacing to increase the statistics.

\subsection{Neutron log response}

We examined the capabilities of the method with a $\mathrm{Cu}$ cylinder $5 \mathrm{~cm}$ in diameter and $20 \mathrm{~cm}$ in length. In this example, the sample was located $9 \mathrm{~cm}$ from the center of the borehole at a depth of $110 \mathrm{~cm}$. Source-detector spacing was $20 \mathrm{~cm}$. Gammaray spectra from the simulation were generated at different depths by lowering the neutron logging tool in steps of $10 \mathrm{~cm}$ inside the borehole. The measuring point was the mid-point of the source-detector distance. Figure 7 shows the gamma-ray 


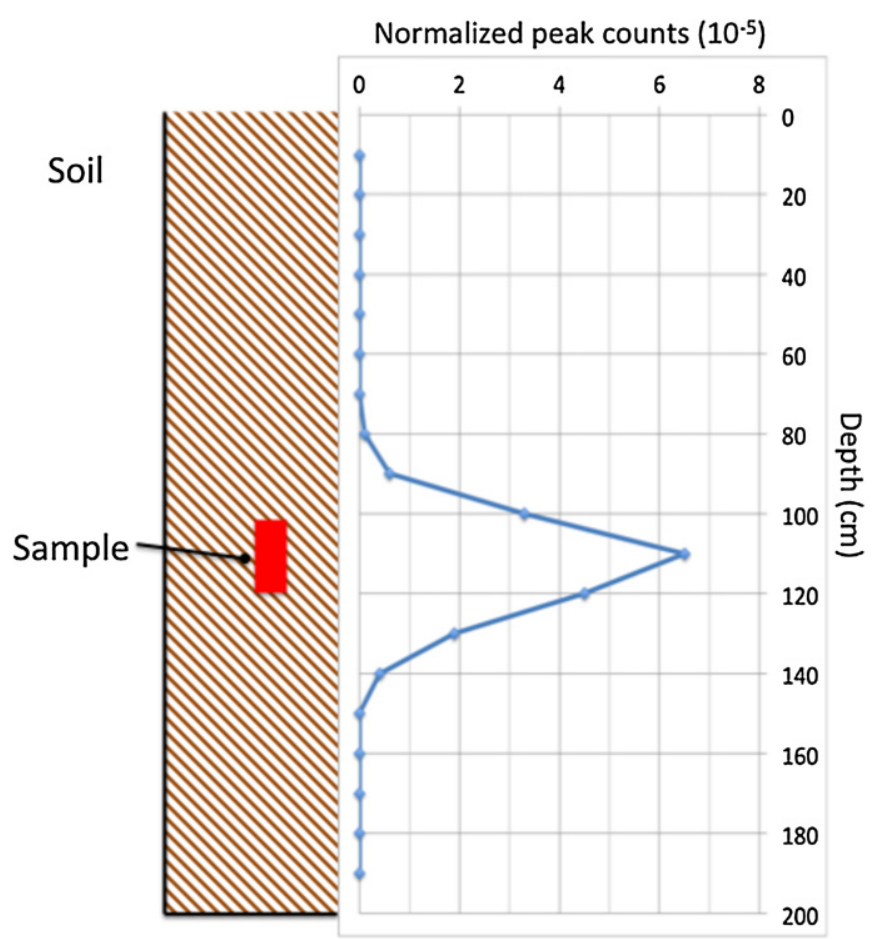

Figure 8. Simulated neutron log response for a zone containing a buried $\mathrm{Cu}$ sample.

spectra at different depths normalized for the number of simulated events. The $\mathrm{Cu}$ peak intensity is maximum at $110 \mathrm{~cm}$ in correspondence with the vertical location of the sample. Figure 8 shows the simulated neutron response log, i.e. the number of counts under the strongest $\mathrm{Cu}$ peak $(7.916 \mathrm{MeV})$ as a function of depth. The response log shows a net increase of $\mathrm{Cu}$ counts at a depth of $110 \mathrm{~cm}$.

\section{Conclusion}

A new archaeological subsurface survey method based on neutron gamma-ray logging was described. Irradiation volume, sampling volume and neutron response log were simulated with the Geant 4 Monte Carlo code. The irradiation volume in soil was $3 \mathrm{~m}^{3}\left(1.3 \mathrm{~m}^{3}\right)$ for a D-T (D-D) source. Results on sampling volume show that an increase of the source-detector spacing corresponds to an increase of the sampling volume and a decrease in the count rate. The source-detector spacing should be carefully chosen so as to optimize the volume of investigation and the acquisition time. A simulated neutron response log displays the ability of the neutron logging system to localize a copper cylinder. This work indicates that neutron-gamma logging can be used as a survey method, in particular in archaeological fields with buried metallic artifacts. The technique is well suited to complement existing surveying methods having different probe volumes and precisions, such as aerial survey and geophysical techniques. Further studies on detection limits and position resolution are planned.

\section{Acknowledgments}

Computing resources of the Science and Technology Facilities Council's e-Science facility were used in this research. This work was partially supported by the CNR-STFC agreement no. 06/20018 concerning collaboration in scientific research at the spallation neutron source ISIS.

\section{References}

[1] Hester T R, Heizer R F and Graham J A 1975 Field Methods in Archaeology (Mountain View, CA: Mayfield)

[2] Pontecorvo B 1941 Neutron well logging: a new geological method based on nuclear physics Oil Gas J. 4032

[3] Committee on Radiation Source Use and Replacement, National Research Council 2008 Radiation Source Use and Replacement: Abbreviated Version (Washington, DC: National Academies Press)

[4] Miceli A, Senesi R, Andreani C, Festa G, Gorini G and Perelli-Cippo E 2013 A neutron-gamma logging system for applications to cultural heritage: a Monte Carlo study Titolo e autori, in Fotonica 2013, 15 Convegno Nazionale delle Tecnologie Fotoniche, Milano, 21-23 maggio 2013 (Milan: AEIT) ISBN 9788887237160, ISBN-A $10.978 .8887237 / 160$

[5] Miceli A, Festa G, Senesi R, Gorini G, Perelli-Cippo E, Cattaneo R and Andreani C 2013 On-site neutron logging for cultural heritage applications: a Monte Carlo study Proc. 17th Int. Conf. on Cultural Heritage and New Technologies (Wien) (Vienna: Museen der Stadt Wien-Stadtarchäologie)

[6] Agostinelli S et al 2003 G4-a simulation toolkit Nucl. Instrum. Methods Phys. Res. A 506 250-303

[7] Allison J et al 2006 Geant4 developments and applications IEEE Trans. Nucl. Sci. 53 270-8

[8] Serra O 1984 Fundamentals of Well-log Interpretation. Part 1: The Acquisition of Logging Data (Amsterdam: Elsevier)

[9] Molnar G L 2004 Handbook of Prompt Gamma Activation Analysis (Dordrecht: Kluwer)

[10] Foderaro A 2003 The Elements of Neutron Interaction Theory (Cambridge, MA: MIT Press)

[11] Wightman W E, Jalinoos F, Sirles P and Hanna K 2003 Application of Geophysical Methods to Highway Related Problems Federal Highway Administration, Central Federal Lands Highway Division, Lakewood, CO, Publication No. FHWA-IF-04-021

[12] Hoover A S et al 2009 Simulation and modeling for the stand-off radiation detection system (SORDS) using GEANT4 IEEE Nucl. Sci. Symp. pp 914-7

[13] Bodnarik J et al 2013 Time resolved neutron gamma ray data acquisition for in situ subsurface planetary geochemistry Nucl. Instrum. Methods Phys. Res. A 707 135-42 